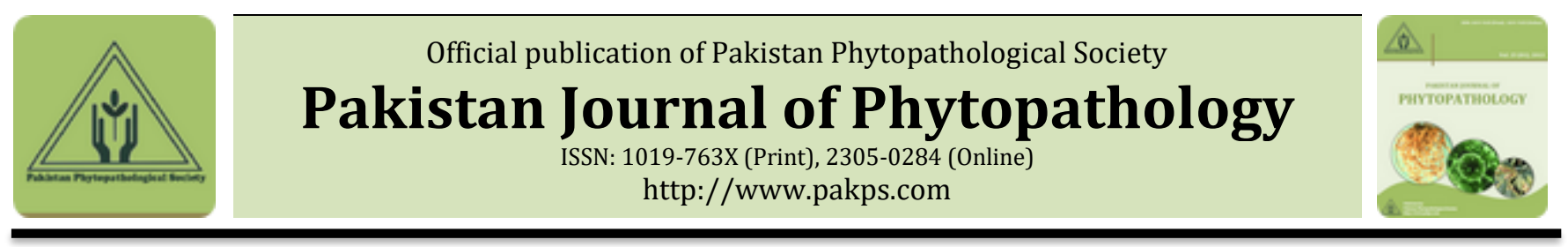

\title{
ANTIFUNGAL POTENTIAL OF COMMERCIALLY AVAILABLE FUNGICIDES AGAINST ALTERNARIA BLIGHT OF BRASSICA
}

\author{
aAhmed Subhani, aMuhammad Atiq, aNasir A. Rajput, cMuhammad R. Bashir, aMuhammad Asif, \\ ${ }^{b}$ Shakila Kauser, aYasir Ali, a Akhtar Hameed, anoor Muhammad, ${ }^{\text {dKomal Mazhar }}$ \\ ${ }^{a}$ Department of Plant Pathology, University of Agriculture Faisalabad, Pakistan. \\ ${ }^{b}$ Department of Botany, University of Agriculture Faisalabad, Pakistan. \\ c Oilseeds Research Institute, Ayub Agricultural Research Institute, Faisalabad, Pakistan. \\ d Department of Forest and Rangeland Management, University of Agriculture Faisalabad, Pakistan.
}

\section{A B S T RA C T}

Brassica campestris is the leading oilseed crop of Pakistan. It fulfills $20 \%$ oil requirement of Pakistan. This crop is affected by various biotic and abiotic factors. Among all other yield limiting biotic constraints, Alternaria blight, caused by Alternaria brassicae playes imperative role. In the current research fifteen advanced lines/genotypes (Punjab Canola, Faisal Canola, Shirale, Dunkeld, Rainbow, AC-Excel, Legend, Oscar, Cyclone, Con II, Con III, Bulbul 98, DGL, B.S.A, Toria selection) were sown at Department of Plant Pathology with three replications under Completely Randomized Block Design (RCBD) by maintaining the plant to plant $(\mathrm{P} \times \mathrm{P})$ distance of $45 \mathrm{~cm}$ and bed to bed $(\mathrm{B} \times \mathrm{B})$ distance of $75 \mathrm{~cm}$. Two genotypes i.e. Punjab canola (48.83\%), Faisal canola (50.06\%) exhibited moderately resistant response. Similarly, eight commercially available fungicides namely Rally 40\% WP (Myclobutanil 40\%), Chlorotoxin (Azoxystrobin 5.4\%+Chlorothalonil 45\%), Alliette 80\% WP (Fosetyli-Aluminium 80\%), Success 70\% WP (Metalaxyl 8\% + Chlorothalonil 64\%), Swing 72\% (Metalaxyl 8\% +Mancozeb 64\%), Cytrol 75\% (Thiophanate-methyl 35\% + Chlorothalonil 40\%), Antracol (Propineb 70\%) and Score 250 EC (Difenconazole 250EC) were used with two concentrations viz. $0.25 \%$ and $0.50 \%$ of each fungicide under filed conditions with three replication and Randomized Complete Block Design. It was observed that both concentrations $(0.25 \%$ and $0.50 \%)$ of swing played statistically significant role to inhibit the disease incidence. Therefore, it is concluded that Punjab Canola and Faisal Canola are statistically reliable advanced lines as compared to all other thirteen advanced lines/ genotypes. Likewise, the concentrations $0.25 \%$ and $0.50 \%$ of swing have statistically more potential to retard the disease incidence as compared to all other commercially available fungicides.

Keywords: Mustard, Brassica, Alternaria blight, Antifungal, Management.

\section{INTRODUCTION}

Brassica campestris is the most important edible oilseed crop of the world due to it's wider contribution to enhance the production of oilseed crops per acre up to 19\% and $28 \%$ (Bnadopadhaya et al., 2013). Rapeseed and mustard are fulfilling most of the oil requirement of the world. It contains beta-carotene, vitamin C, beneficial

Submitted: April 19, 2018

Revised: May 30, 2018

Accepted for Publication: June 20, 2018

* Corresponding Author:

Email: mrizwan1526@gmail.com

(C) 2017 Pak. J. Phytopathol. All rights reserved. fiber and extracted oil contains $35-38 \%$ protein contents. It is cultivated in tropical and subtropical regions of the world. It is grown on an area of 30 million hectares with a production of 59.6 million tones in the world (Meena et al., 2016) whereas in Pakistan, it is cultivated on an area of 195 thousand hectares with the production of 185 thousand tons during 2014-2015 (Pakistan Economic Survey, 2014-2015). The total extracted edible oil from this crop is $18-20 \%$ while $80 \%$ is imported to fulfill the demands of edible oil consumption in Pakistan (Abbas et al., 2009, Asif et al., 2017).

Various diseases are disturbing the successful production of various brassica species. Among those 
constraints, Alternaria blight is the most destructive one in the entire world. It has caused epidemic damage in Canada, UK (Humpherson and Phelps, 1989; Mridha and Wheeler, 1993; Hong and Fitt 1996) and India (Ansari et al., 1988). A. brassicae is mainly responsible for significant yield reduction and quality deterioration in brassica (Verma and Saharan, 1994). Alternaria blight caused by Alternaria brassicae was reported in the early 20th century. First time A. brassicae described by Saccardo, (1880). The pathogen affects different host species at all stages and deteriorate the quality of the oil. The disease appears after 45 days after growing and a severe attack can be seen after 75 days (Meena et al., 2016). The yield losses of $10-60 \%$ have been reported on this crop in case of severe attack under conducive condition (Meena et al., 2016). Pathogen Decreases the rate of photosynthesis, causes shattering of the premature pod, increases senescence and production of shriveled seeds are the characteristic symptoms of this disease (Shresta et al., 2000). Symptoms of Alternaria blight appears on the older leaves, stems, seedlings and on pods. On leaves first, tan color spots appear which gradually increases and reduce the photosynthetic rate (Kubota et al., 2003). When A. brassicae attacks at seedling stage, dark lesions appear on the stem while brown to black spots appear on hypocotyl at the seedling stage which decreases plant growth (Valkonnen and Koponnen, 1990).

Fungus infection on host occurs by adhesion on surface, penetration leading to growth in the tissue. Management of disease is a very important step to avoid rapid losses. Different scientists used various methods such as the application of chemicals, plant activators, and plant extracts to manage this disease but the resistant germplasm is most conventional method to diminish disease severity. Genetic resistance is only best choice to manage the disease as it is ecologically safe, native adapted to the local environment, and durable. In the absence of resistant cultivars, fungicides are used to manage the diseases due to its quick action to suppress the diseases severity, easy and abundant availability in the market (Verma and Saharan, 1994; Khan et al., 2007; Sultana et al., 2009). Unavailability of resistant varieties forces the farmers to grow susceptible germplasm (Asif et al., 2017). In spite of extensive work on genetic resistance development in brassica, neither of the germplasm is found resistant against this fungus while several other practices to control this disease are proving less effective. When there is a severe outbreak of disease, farmers require quick control, for this purpose use of commercial fungicides become a necessity to give robust solution against the disease, To tackle such situation, research was planned to screen the available germplasm for the source of resistance and evaluate the efficacy of commercially available fungicides against Alternaria brassicae.

\section{MATERIALS AND METHODS}

The experiment was conducted in the research area of Department of Plant Pathology, the University of Agriculture Faisalabad in January 1, 2016. Fifteen rapeseed cultivars i.e. Punjab Canola, Faisal Canola, Shirale, Dunkeld, Rainbow, AC-Excel, Legend, Oscar, Cyclone, Con II, Con III, Bulbul 98, DGL, B.S.A, Toria selection "A" were taken from Oilseed Research Institute of Ayub Agricultural Research Institute (AARI), Faisalabad, Pakistan and was planted on flatbed surface under Randomized Complete Block Design (RCBD) with $\mathrm{P} \times \mathrm{P}$ distance $45 \mathrm{~cm}$ and $\mathrm{R} \times \mathrm{R}$ distance $75 \mathrm{~cm}$ with three replications of each variety. All the cultural practices were performed to keep the crop in healthy condition. After the screening analysis, only two highly susceptible varieties according to rating scale were selected for fungicides evaluation.

Two varieties of brassica (DGL and BSA) were collected from Oilseed Research Institute, Ayub Agricultural Research Institute (AARI), Faisalabad. These varieties were planted on flat bed surface under Randomized Complete Block Design (RCBD) with plant to plant $(\mathrm{P} \times \mathrm{P})$ distance $45 \mathrm{~cm}$ and bed to bed $(\mathrm{B} \times \mathrm{B})$ distance 75 $\mathrm{cm}$ with three replications of each variety. The size of the plot was adjusted to $10 \times 10 \mathrm{ft}$ with four rows. All the cultural practices were performed to keep the crop in healthy condition with the application of standard doses of fertilizers. Eight commercial fungicides (Rally 40\% WP (Myclobutanil 40\%), Chlorotoxin (Azoxystrobin 5.4\%+Chlorothalonil 45\%), Alliette 80\% WP (Fosetyli-Aluminium 80\%), Success 70\% WP (Metalaxyl 8\% + Chlorothalonil 64\%), Swing 72\% (Metalaxyl 8\% +Mancozeb 64\%), Cytrol 75\% (Thiophanate-methyl 35\% + Chlorothalonil 40\%), Antracol (Propineb 70\%) and Score 250 EC (Difenconazole 250EC)) were bought from local market. Two concentrations i.e. $0.25 \%$ and $0.50 \%$ were made by dissolving $25 \mathrm{~mL}$ and $50 \mathrm{~mL}$ from a stock solution in a $250 \mathrm{~mL}$ beaker while the total volume of $100 \mathrm{~mL}$ was adjusted by adding water. Hand sprayer 
(HECHT-401, Model: HT-401) was used to apply the foliar concentration of spray on each row of variety. Untreated rows of each variety/lines in each block served as control. The first spray of the fungicides was applied by Hand sprayer (HECHT-401, Model: HT-401) after one month of sowing and just after the appearance of initial symptoms in the field. The first spray was carried out immediately after the appearance of the disease symptoms and repeated after seven days of interval. Disease symptoms were recorded on the basis of visual observations according to disease rating scale at the initiation of primary disease symptoms and continued till the maturity of the crop. Data was collected on a weekly basis whereas disease incidence was calculated by using following formula:

$$
\text { Disease incidence }(\%)=\frac{\text { No. of infected plants }}{\text { Total No. of plants }} \times 100
$$

Table 1. Disease rating scale for Alternaria blight of brassica caused by A. brassicae

\begin{tabular}{cccc}
\hline Disease Rating & Description & Response & Symbol \\
\hline 0 & 0 & Immune & $\mathrm{I}$ \\
\hline 1 & $1-10 \%$ & Highly Resistant & $\mathrm{R}$ \\
\hline 2 & $11-20 \%$ & Resistant & MR \\
\hline 3 & $21-30 \%$ & Moderately resistant & MS \\
\hline 4 & $31-50 \%$ & Susceptible & $\mathrm{S}$ \\
\hline 5 & $51-75 \%$ & Highly Susceptible & HS \\
\hline 6 & $>75 \%$ & &
\end{tabular}

Li et al., (2007).

\section{STATISTICAL ANALYSIS}

All the statistical tests were performed by using SAS statistical software (SAS Institute, 1990). Means were separated by using Fisher's protected least significant difference (LSD) procedure by taking $\mathrm{P}=0.05 \%$ probability level (Steel, et al., 1997). Analysis of variance (ANOVA), interaction of different treatments and their combinations were developed by using SAS/STAT software package.

\section{RESULTS AND DISCUSSION}

Out of fifteen varieties, two brassica lines showed moderately susceptible response i.e. Punjab canola
(48.83\%), Faisal canola (50.06\%) disease incidence with a disease rating of 4 . While ten varieties/lines expressed susceptible response i.e. Bulbul98(75.40\%) Con III (72.5\%) AC Excel (65.4\%) Cyclone (60.733\%) Rainbow (59.9\%) Oscar (58.733\%) Legend (57.733\%) Con-II (57.667\%) Dunkeled (52.567\%) Shiralee (51.633\%) disease incidence (under disease rating 5). Similarly, three varieties i.e. BSA (78.3\%), DGL (79.567\%) and Toria selection A (80.0\%) exhibited disease incidence with a disease rating of 6 (Figure 1)

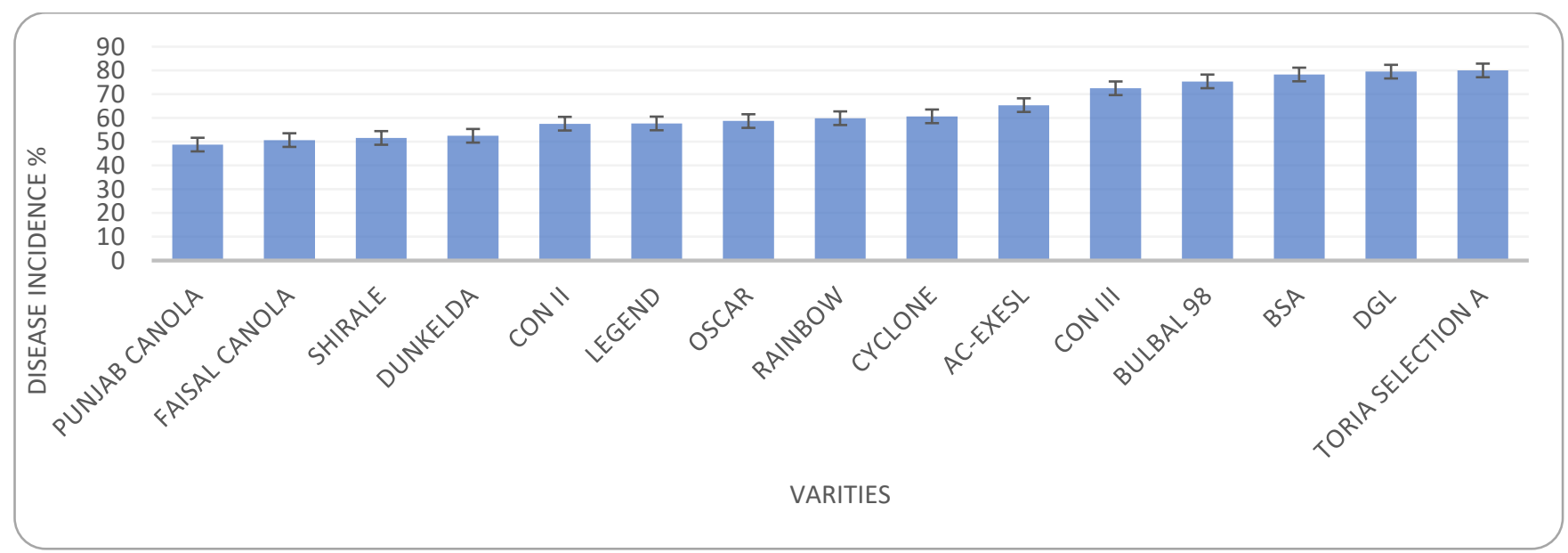

Figure 1. The response of Brassica varieties/lines against Alternaria blight disease under field conditions.

All treatments, concentrations, varieties and their interactions with each other showed significant results against Alternaria blight disease. There were eight fungicides applied on brassica leaves against 
Alternaria blight and efficiency of these fungicides were found statistically satisfactory to reduce disease incidence as compared to control. Among all fungicides control efficiently minimized the disease incidence up to (32.33\%) and Swing (32.81\%) as compared to control (79.56\%). Other fungicides namely Success, Antracol, Score, Chlorostrobin, Rally and Allete Showed the disease up to $(36.04 \%, 44.48 \%$, $49.67 \%, \quad 55.729 \%, \quad 61.303 \%$, and $65.333 \%)$ respectively (Figure.2)

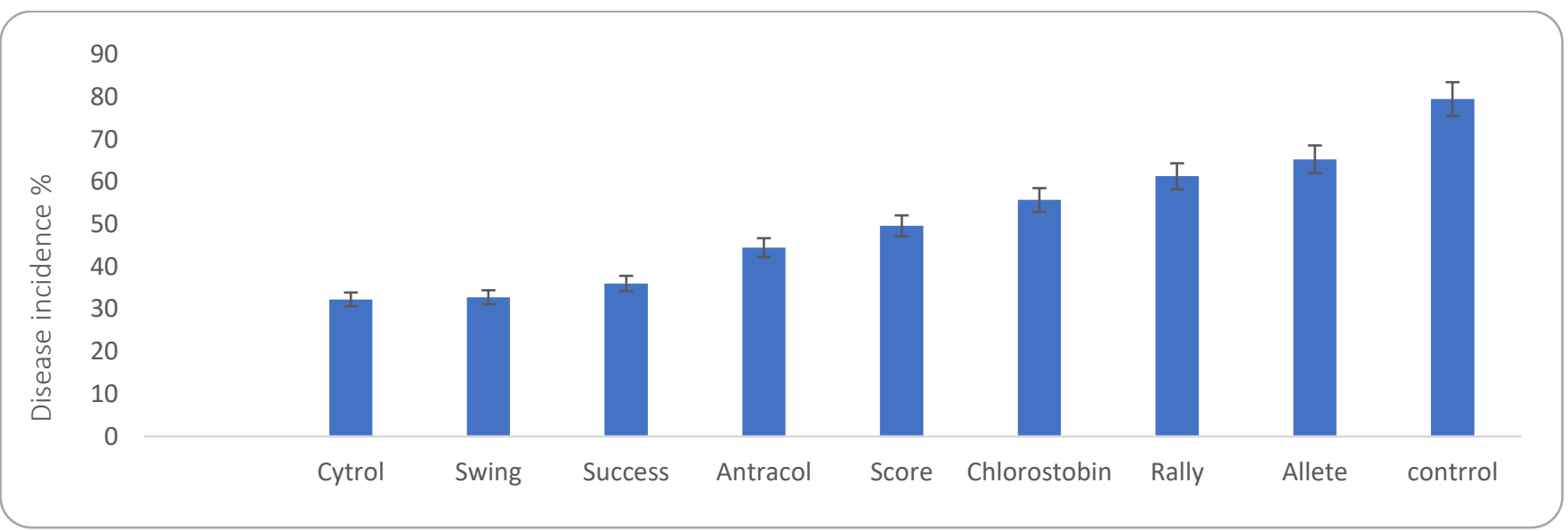

Figure. 2. Efficacy of different fungicides against Alternaria blight disease of Brassica.

Interaction of treatments with concentration expressed that both concentrations of Control followed by Swing resulted in a maximum reduction in disease incidence while Score, Chlorostrobin, Rally and Alliete demonstrated very less effective results. Success and Antracol depicted average results as compared to less efficient fungicides. Disease incidence recorded after the application of Cytol and Swing was 32.9\% and 33.09\% with concentration of $0.25 \mathrm{~mL} / 100 \mathrm{~L}$ and $31.6 \%$ and $32.5 \%$ with $0.5 \mathrm{~mL} / 100 \mathrm{~L}$ concentration respectively. It can be concluded that both these fungicides have effective antifungal potential on Alternaria blight. In addition, application of less efficient fungicides is not suitable for better management. Both concentrations of Alliete and Rally showed very low action against disease (Figure 3)

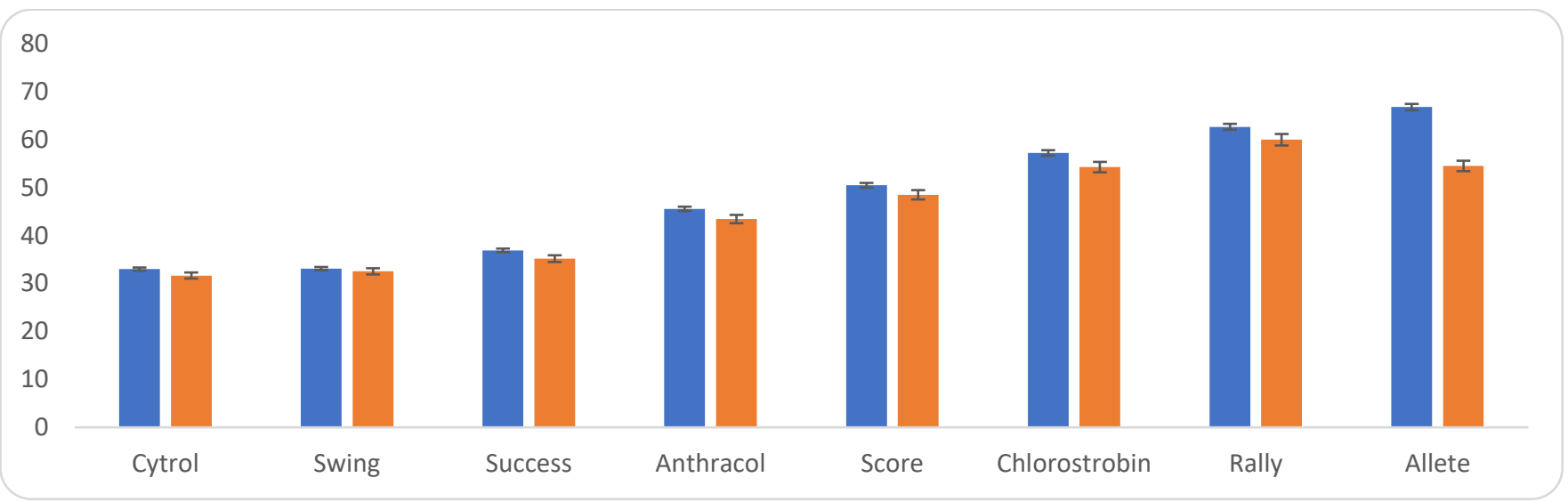

Figure 3. Interaction of different treatments with concentrations against Alternaria blight disease of Brassica.

Interaction of treatment with varieties showed that the effect of Cytrol, and Swing was actively similar to reduce disease incidence up to $31.85 \%$ and $32.55 \%$ on DGL and $32.78 \%$ and $33.06 \%$ ) on BSA. It may be concluded that both varieties can be cultivated and two to three sprays will be enough to manage the disease up to economic level. In addition, the effect of other all fungicides was quite near to each other in controlling the disease. After their application disease incidence was 36.217\%, 43.533\%, 48.925\%, 55.250\%, $59.520 \%$ and $64.250 \%$ respectively while on BSA it was 
$35.867 \%, \quad 45.442 \%, \quad 50.417 \%, \quad 56.208 \% ， \quad 63.084$ and $66.417 \%$ respectively. It can be inferred that this incidence is quite near to the control. That's why their efficiency was less against Alternaria blight (Figure 4)

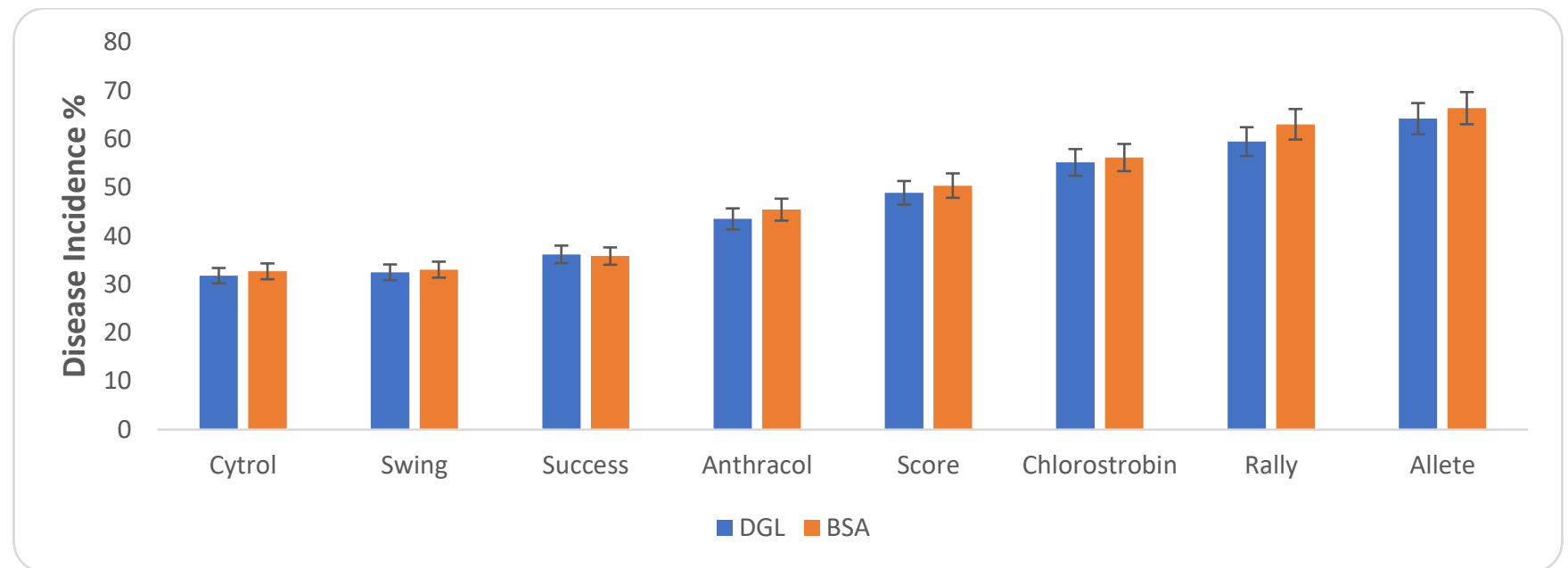

Figure 4. Interaction of different treatments with their concentrations against Alternaria blight disease of Brassica.

Interaction of treatment with concentrations demonstrated that both concentrations of Cytrol, swing and Success are prominently significant in reducing the disease incidence. Comparing both concentrations depicts that $0.50 \%$ concentration of Swing showed (33.09\%) disease incidence as compared to $0.25 \%$ concentration which resulted in $32.52 \%$ disease incidence while comparing it with control former concentration depicted effective results than later. Both concentrations showed less deviation from each other. Cytrol was most effective and its $0.5 \%$ concentration decreased the disease up to (31.65\%) as compared to control (79.56\%). It can also be inferred that this concentration effectively managed the disease and suppressed it to more than 50\%. Later application of these fungicides showed gradually increasing trend of disease incidence on both varieties with each concentration while comparing both concentrations on each variety as application of first concentration $(0.25 \%)$ of Chlorostrobin, Rally and Allette demonstrated disease incidence of $57.21 \%, 62.64 \%$, and $66.75 \%$ respectively while it was increased after the application of second concentration $(0.5 \%)$ to $(54.25 \%$, $59.96 \%$ and $54.49 \%$ ) respectively. Alliete, Rally, and Chlorostrobin were least effective with their both concentrations showing Disease incidence quite nearer to Highest incidence of the control (Figure. 5)

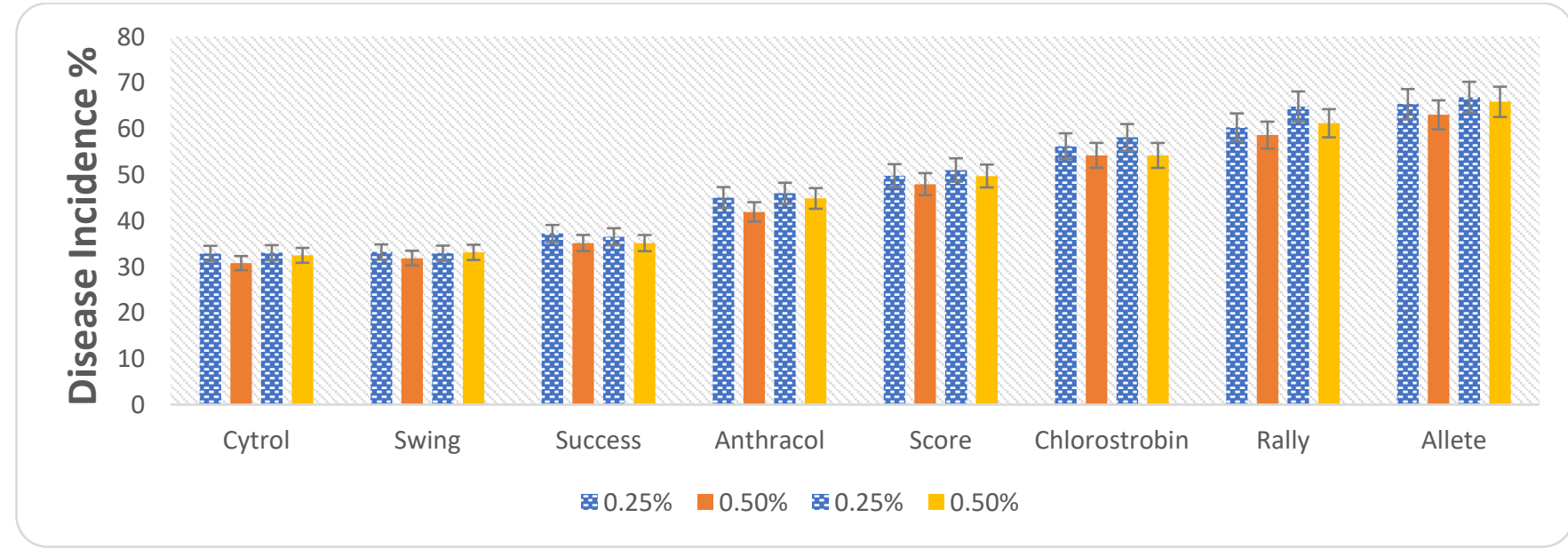

Figure 5. Interaction of different treatments with their concentrations and varieties against Alternaria blight disease of Brassica. 


\section{DISCUSSION}

Timely plantation of disease-free seed after deep plowing, hygienic cultivation, removal of weeds and maintaining proper population helps to control the disease. In the absence of resistant cultivars, fungicides provide the most reliable means of disease control (Bashir et al., 2018). Several applications of fungicides are required to achieve economic yield and acceptable quality in infected crops. Khan et al. (2007) sprayed three systemic fungicides Thiophanate methyl, Ridomil MZ (Mancozeb, 64\%+ Metalaxyl, 8\%), and Carbendazim alone and in combination with four non systemic fungicides i.e. Captan, Mancozeb, Zineb, and Thiram in the field at $0.2 \%$ concentration, among Ridomil MZ was only effective followed by the combination of Carbendazim + Captan. These results significantly justify the results obtained from this experiment. In addition, Singh et al., (2014) reported that three consecutive sprays of Mancozeb resulted in maximum control of Alternaria leaf blight intensity followed by schedule with two consecutive sprays of Mancozeb (0.2\%) and third of Rodomil MZ (0.25\%). Foliar sprays of Mancozeb have been found most effective in disease management (Meena et al., 2004, 2011; Mondal et al., 2008). Mancozeb was the best among all the treatments, resulting in the lowest disease severity on leaves of mustard (Meena et al., 2004). Ridomil MZ-72 WP significantly reduced the disease incidence ranging from 64 to $30 \%$. The findings of current research are prominently similar with reduction range of $40 \%$ in disease after the twice application of swing @ 2.5g/L. Significant increase in seed yield up to $26.4 \%$ was achieved after the application of chemicals. However, fungicidal seed treatment with Apron 35 SD (metalaxyl $35 \%$ ) @ 6 g/Kg seed followed by foliar spray of Ridomil MZ 72 WP @ 2 g/L water after 50-60 days of sowing is found most effective in reducing Alternaria leaf and pod blight up to $54.8 \%$ and $43.1 \%$, respectively. Meena et al., (2011) conducted different experiments to check efficiency of Mancozeb against alternaria blight disease of Brassica. After different trials and observed the reduction in disease incidence up to $64 \%$ and $19 \%$. Similarly, it was also found that chemical fungicides in combination with Eco-friendly products such as $T$. harzianum and Pseudomonas fluorescence showed better results against WR. Similar findings were reported in the current research. Khan et al., (2007) reported that different fungicides and their combinations actively reduced the disease. It was also evaluated that Bavistom, Topsin M and Ridomil MZ were significantly reduced the Alternaria blight of crucifers. Ridomil MZ was found significantly effective for managing disease up to $32 \%$. Topsin M and Ridomil formulations are similar to Swing 72\% (Metalaxyl 8\% + Mancozeb 64\%) 72\% (Metalaxyl 8\% + Mancozeb 64\%) and Antracol (Propineb 70\%) (Propineb 70\%) and the results are in line with the findings of current research. Till date, chemical management was the only option against the problem. It is suggested that these fungicides can be used in the field for effective management of Alternaria blight of brassica.

\section{CONCLUSION}

Fifteen advanced lines/ genotypes of brassica were used in the present research and two advance lines viz. Punjab canola (48.83\%), Faisal canola (50.06\%) exhibited moderately resistant response. Therefore, it is concluded that in future breeding programs these advance lines could be released as commercial cultivars. Similarly both concentration i.e. $0.25 \%$ and $0.50 \%$ of Swing among eight commercially available fungicides expressed statistically maximum reduction in disease. These concentrations of swing might be applicable to hinder Alternaria blight disease incidence of brassica if all other factors were managed appropriately.

\section{ACKNOWLEDGMENTS}

The current research is a part of M.Sc (Hons.) degree; the author acknowledges Dr. Muhammad Atiq, Assistant Professor of the Department of Plant Pathology for their supervision, valuable suggestions, and cooperation throughout this work.

Conflict of Interest: The research was conducted at Department of Plant Pathology and evaluated by the Supervisory committee. Each author of this manuscript played the pivotal role during write up and did not possess any conflict of interest to publish this research in "Pakistan Journal of Phytopathology"

Funding Agencies: The author is fully gratitude to the Department of Plant Pathology, University of Agriculture Faisalabad for providing Lab. facilities but the major funding resources to conduct the research was bearded from authors own resources.

Human Rights and Animal Welfare Statement: The chemicals used in the current research are not banned by "Environmental Protection Agency" as well as they are not applied with higher concentrations as recommended by manufactures. Therefore, the application of low concentrations $(0.25 \%$ and $0.50 \%)$ 
used in the contemporary experiments is not harmful to human beings as well as for animals.

\section{REFERENCES}

Abbas, S. J., M. K. farhat-Ullah, I. Khan and I. Munir. 2009. Molecular analysis of genetic diversity in Brassica species. Pak. J. Bot, 41: 167-176.

Ansari, N., M. Khan and A. Muheet. 1988. Effect of Alternaria blight on oil content of rape seed and mustard. Current Science, 57: 1023-1024.

Asif, M., M. Atiq, S. T. Sahi, S. Ali, A. Nawaz, Y. Ali, A. Subhani and A. Saleem. 2017. Effective Management Of White Rust (Albugo Candida) of Rapeseed Through Commercially Available Fungicides. Pakistan Journal of Phytopathology, 29: 233-237.

Bandopadhyay, L., D. Basu and S. R. Sikdar. 2013. Identification of Genes Involved in Wild Crucifer Rorippa indica Resistance Response on Mustard Aphid Lipaphis erysimi Challenge. PLoS ONE, 8: e73632.

Bashir, M. R., M. Atiq, M. Sajid, M. Mohsan, W. Abbas, M. W. Alam and M. Bashair. 2017. Antifungal exploitation of fungicides against Fusarium oxysporum f. sp. capsici causing Fusarium wilt of chilli pepper in Pakistan. Environmental Science and Pollution Research, 25: 6797-6801.

Hong, C. X., B. D. L. Fitt and S. J. Welham. 1996. Effects of wetness period and temperature on development of dark pod spot (Alternaria brassicae) on oilseed rape (Brassica napus). Plant Pathology, 45: 10771089.

Humpherson-Jones, F. M. and K. Phelps. 1989. Climatic factors influencing spore production in Alternaria brassicae and Alternaria brassicicola. Annals of Applied Biology, 114: 449-458.

Khan, M. M., R. U. Khan and F. A. Mohiddin. 2007. Studies on the cost-effective management of Alternaria blight of rapeseed-mustard (Brassica spp.). Phytopathologia Mediterranea, 46: 201-206.

Kubota, K., S. Tsuda, A. Tamai and T. Meshi. 2003. Tomato mosaic virus replication protein suppresses virus-targeted posttranscriptional gene silencing. Journal of virology, 77: 1101611026.

Li, C. X., K. Sivasithamparam, G. Walton, P. Salisbury, W. Burton, S.S Banga, C. Chattopadhyay, A. Kumar, R. Singh, D. Singh, A. Agnohotri, S. Y. Liu, Y.C. Li, T. D. Fu, Y. F. Wang, and M.J. Barbetti. 2007. Expression and relationships of resistance to white rust (Albugo candida) at cotyledonary, seedling, and flowering stages in Brassica juncea germplasm from Australia, China, and India. Australian Journal Agriculture Research, 58: 259-264.

Meena, P. D., R. L. Meena, C. Chattopadhyay and A. Kumar. 2004. Identification of Critical Stage for Disease Development and Biocontrol of Alternaria Blight of Indian Mustard (Brassica juncea). Journal of Phytopathology, 152: 204-209.

Meena, P., C. Chattopadhyay, A. Kumar, R. Awasthi, R. Singh, S. Kaur, L. Thomas, P. Goyal and P. Chand. 2011. Comparative study on the effect of chemicals on Alternaria blight in Indian mustardA multi-location study in India. Journal of environmental biology, 32: 375.

Meena, P., R. Awasthi, C. Chattopadhyay, S. Kolte and A. Kumar. 2016. Alternaria blight: a chronic disease in rapeseed-mustard. Journal of Oilseed Brassica, $1: 1-11$.

Mondal, L., C. Bhunia and A. Baswas. 2008. Efficacy of new bio-fungicides in vivo against Alternaria blight disease of rapeseed-mustard. Green Farm, 1: 41-44.

Mridha, M. A. U. and B. E. J. Wheeler. 1993. In vitro effects of temperature and wet periods on infection of oilseed rape by Alternaria brassicae. Plant Pathology, 42: 671-675.

Saccardo, P. 1881. Fungi Veneti novi vel critici v. Mycologiae venetae addendi. MicheliaCommentarium Mycologicum, 2: 241-301.

Sas, S. 1990. STAT User's Guide, Version 6, SAS Institute. Inc. Cary, NC, US, A.

Shrestha, S., S. Mathur and L. Munk. 2000. Alternaria brassicae in seeds of rapeseed and mustard, its location in seeds, transmission from seeds to seedlings and control. Seed Science and Technology (Switzerland), 28: 75-84.

Singh, M., R. Gupta, H. Singh, A. Kumar and A. Kumar. 2014. Morphological Variability in Alternaria brassicae Isolates of Indian Mustard, Brassica juncea L. Czern. \& Coss. Trends in Biosciences, 7: 2382-2384.

Steel, R. G. D., J. H. Torrie and D. A. Dickey. 1997. Principles and procedures of statistics. A biometrical approach. $3^{\text {rd }}$ Edit. McGraw Hill Pub. Co., New York.

Sultana, N. A. M. A. H. K., M. N. Islam and K. Nahar. 2009. 
Evaluation of appropriate time for the application of rovral Technology. 28: 75-84.

Valkonen, J. and H. Koponen. 1990. The seed-borne fungi of Chinese cabbage (Brassica pekinensis), their pathogenicity and control. Plant Pathology, 39:
510-516.

Verma, P. and G. Saharan. 1994. Monograph on Alternaria diseases of crucifers, Saskatoon Research Centre Technical Bulletin 1994-6E. Agriculture and Agri-Food Canada, Saskatoon. 